\title{
What can parents do? The causal mediating role of parenting in SES differences in children's language development
}

\author{
Alejandra Rodríguez Sánchez
}

\begin{abstract}
This study estimates how much of the effect of parental socioeconomic status (SES) on children's language development is mediated through parenting styles, practices, and parental investments and whether the effects of early literacy-related parenting practices are heterogeneous. Previous studies suggest SES gaps in language skills among preschoolers result from differences in parenting. However, the extent to which parenting mediates the effects of growing up in low-SES contexts, and whether parenting may have heterogeneous effects are still unknown. This paper uses data from the National Educational Panel Study starting cohort 1, a random sample of N=1892 children born between 2012 and 2013 in Germany. The paper uses latent class analysis to measure SES and joint mediation analysis to estimate the mediated share of the SES effect on children's language going through parenting. Quantile regression is used to explore heterogeneity in the effects of parenting practices to further explain the mediated share. Parenting explains or mediates around half of the total effect of SES, and the positive effect of parenting practices are heterogeneous, affecting mostly children around the first quartile of the distribution of language skills. Although a large chunk of the SES
\end{abstract}


effect operates through parenting, and parenting practices positively impact children, their effects on reducing gaps in language skills are limited. Interventions on parenting should not neglect the alternative pathways through which inequality in language skills may be still transmitted.

Keywords: parenting; language development; causal mediation; social inequality.

The substantial inequalities observed in children's language development by parental socioeconomic status (SES) are often attributed to differences in parenting (Duncan, ZiolGuest, and Kalil 2010; Fomby and Musick 2018). This because SES gaps emerge before children enter school and tend to remain stable throughout children's school careers (Skopek and Passaretta 2020). This literature often distinguishes between parenting styles, parenting practices or daily activities, and parental investments as different dimensions of the concept of parenting. Parenting style, which describes the type of parent-child interaction (authoritative, emotional, sensitive, detached, or authoritarian; Baumrind 2005; Kuppens and Ceulemans 2019). Parenting practices referring to the daily activities, such as attending to the child's basic needs or promoting the language and reading skills of the child, and their socio-emotional development (Cobb-Clark, Salamanca, and Zhu 2019; Kalil, Ryan, and Chor 2014); as well as through the cultivation of literacy at home (Melhuish et al. 2008). Parental investments, although often considered together with parenting styles and practices, refer more to the time and financial resources parents invest in their children in the form of goods/services such as childcare, books for children, or other cognitively stimulating activities (Doepke, Sorrenti, and Zilibotti 2019; Miller et al. 2020). Various studies support this view. The effects of authoritarian or detached parenting styles (Chan and Koo 2011); 
the effects of the differences in reading-time with children (Kalil, Ryan, and Corey 2012); and the effects of the lower levels of parental investments (Doepke, Sorrenti, and Zilibotti 2019) help explain structural inequalities by SES because such parenting is more characteristic of low-SES families. Parenting interventions and early childhood programs, in turn, focused on teaching low-SES parents the right set of parenting skills, broadly understood, deemed necessary for effective child development (Ayoub, Vallotton, and Mastergeorge 2011; J. J. Heckman, Humphries, and Kautz 2014; Price 2010). Although parenting covers a large scope of practices and activities that parents do with their children and is difficult to exactly differentiate them, concerning language development, for example, Hoff (2013) and Romeo et al. (2018) trace differences by SES to gaps in some of those parenting dimensions.

Even though specific types of parenting may have positive effects on children, little is known as to what share of the total effect of SES is mediated through parenting, a quantity of relevance for early childhood public policy. Previous studies suggest the link between SES inequalities and inequalities in children's cognitive development cannot be fully accounted for by parenting behaviors (Sullivan, Ketende, and Joshi 2013), therefore, in this study, I explore and estimate the mediated share of the SES effect on language skills that "goes through" parenting, broadly understood. To achieve this, I follow the suggestion of previous research and use a broader conception of parenting when estimating these effects (Fomby and Musick 2018; Mollborn 2016). To address this, I estimate the share of the SES effect that is jointly mediated through multiple parenting mediators employing joint mediation analysis, as explained in VanderWeele and Vansteelandt (2014).

In addition to that, and as an attempt at explaining the results of the joint causal mediation 
analysis, I further explore the potential for heterogeneity by children's language skill level in the effects of early-literacy parenting practices, an unexplored topic in this literature. Even though the effects of parenting on children are not disputed, there is still debate as to the potential for these effects to be heterogeneous, as suggested by qualitative research (Conger, Conger, and Martin 2010). Recent discussions around the effects of mother-time on children's development have called for alternative explorations of this topic in some or all of these parenting dimensions (Milkie, Nomaguchi, and Denny 2015; Nomaguchi, Milkie, and Denny 2016; Waldfogel 2016; and Kalil and Mayer 2016). The fact that parents of different social classes are equally supportive of parenting styles such as intensive mothering and fathering (Ishizuka 2019), coupled with evidence suggesting that some domains may be impacted by parenting, whereas others may not (Duncan et al. 2019), suggests that there is room for exploring heterogeneity in the association between specific parenting dimensions and language development, instead of focusing on deficits only. It is expected that children with lower levels of language skills will be more affected by parenting than children with higher levels. To explore this, I employ quantile regression for the effects of parenting practices related to the promotion of literacy skills on language development indicators measured at various time points.

This paper uses a large observational prospective study of Germany-born children whose language skills have been measured through multiple language standardized assessments. It addresses two research questions: 1) what share of the SES effect is mediated through parenting (i.e., including parenting styles, practices, and investments, as well as other parentingrelated characteristics that may affect these dimensions and that are affected by SES such 
as child care availability, working hours, and parental leave)? And following this, 2) is there quantitative evidence supporting the hypothesis of heterogeneous effects of early literacy parenting practices?

On the one hand, the results of joint mediation analysis show that the share of the effect of SES that is mediated through parenting reaches, at most, around half of the total effect. Therefore, although differences in parenting might explain a modest, though substantial, share of the language skill gaps by SES, a sizeable share of the effect remains "unmediated", or goes through other alternative pathways. On the other hand, quantile regression estimates suggest that there is heterogeneity in the effects of parenting practices related to literacy, which might be a potential explanation for the limited effect of parenting on language development.

\section{BACKGROUND}

\section{Parenting styles, parenting practices, and parental investments,}

\section{and SES}

Multiple studies show that parenting is without a doubt an active ingredient in children's developmental trajectories (Grusec 2011; Maccoby 2000). Parenting is thought to constitute the main process through which social inequalities are reproduced (Guo and Harris 2000). Both the family stress model and the family investment model suggest parenting is, if not the main, one important mechanism linking children's development trajectories and SES (Conger, Conger, and Martin 2010; Duncan et al. 1998). Although parenting dimensions 
are conceptualized as distinct from one another, recent research suggests that these are not independent of one another, and that, therefore, their effects on children's development should perhaps be considered jointly (Elliott and Bowen 2018; Mayer et al. 2019). Such is the case of research on the parenting package (Fomby and Musick 2018), as well as on the effects of developmental ecologies (Mollborn 2016). For the causal mediation analysis proposed in this paper, such conceptualization of parenting suggests more complex pathways through which parents' SES may influence children's development through parenting, which should be accounted for when trying to unbiasedly estimate the mediated effect of SES through anyone parenting dimension (VanderWeele and Vansteelandt 2014).

In turn, the strong working assumption of independent mediators, on which previous studies have relied, seems inappropriate for the study of parenting as a mediator of the SES effects (for example, T. Linberg et al. 2019). This nonindependence between mediators has been suggested by the literature on evaluations of parenting and early childhood interventions. These interventions, which are interventions on parents and their childrearing behavior, focus on changing more than one aspect of parenting, and instead, they intervene on multiple parenting aspects that are considered beneficial (Madigan et al. 2019). The Nurse-Family Partnership Program, for example, was designed to impact multiple of these parenting dimensions instead of just one (J. Heckman et al. 2014), often under the assumption that parenting affects more than one of those proximal processes (Bronfenbrenner and Morris 2007) Regarding causal mediation, because these different parenting dimensions interact with one another (i.e., parental investments may affect parenting practices and styles, or vice-versa), and because SES affects all dimensions related to parenting, a causal mediation 
analysis should account for the potential causal associations between mediators, as well as for the confounding factors of those associations which are affected by SES (VanderWeele and Vansteelandt 2014), as in exposure (or treatment) induced mediator-outcome confounding (e.g., child care effects, affected by SES, have also an effect on parental investments). In general, when these associations are present, it is not possible to estimate the specific effect of single pathways, which remain unidentified, that is, they can only be estimated with bias. Instead, to estimate what share of the SES effect is mediated through parenting, substantive knowledge from the parenting literature and contemporary methods in mediation analysis suggests that it is necessary to consider jointly all the pathways through which parenting can influence children's well-being.

\section{Heterogenous effects of parenting}

Moreover, the effects of parenting might be heterogeneous as a consequence of families being embedded within specific contexts around which family life is organized (Manstead 2018). Parenting mediators are crucially linked because they are related by the broader contexts in which family life takes place. Parents of different SES are not only unequally endowed with resources and skills, they are unequally constrained by factors such as time and working conditions that also have effects on their parenting (Bradley and Corwyn 2002). For example, studies have shown that middle-class parents engage in parenting practices that have been characterized as concerted cultivation, with beneficial effects for middle-class children, whereas working-class and working-poor-class families' parenting is more similar to the accomplishment of natural growth, which may not provide the same benefits (Lareau 2011: 
pp. 238-239). On top of that, other qualitative research suggests that social inequalities in children's language skills result from the interaction between social class origins and teachers' or caregivers' differential expectations about children's behavior and language (Millet and Croizet 2016). Therefore, parenting is something done by unequal parents and in unequal circumstances, and because those parents are distinctively positioned in the social structure, SES affects parenting and children's development through more intricate pathways (Lahire 2019).

The main theories that explain the connection between SES, parenting, and children's cognitive development fundamentally rely on such complex interactions. The family investment model, for instance, considers that differences in resources and parental investments explain the differences in cognitive development (Duncan et al. 1998). The family stress model, in turn, considers that the stress caused by low resources negatively affects parents' behavior with their children (Conger, Conger, and Martin 2010). Thus, these models argue precisely about multiple and nonindependent pathways that link SES to parenting. Low-SES parents might have a heavier work-load and receive lower wages, which implies higher levels of tiredness, stress, and, perhaps, less leisure time to spend with their children, all of which may produce a less effective type of parenting (Milkie, Raley, and Bianchi 2009). In contrast, high-SES parents may be more able to hire or pay for extra parenting provided by others in the form of cognitively stimulating activities with care professionals, even from early on (Schober and Schmitt 2017); which may positively impact the parent-child relationship by taking some of the burden of care work from parents' shoulders. The effects of the same parenting practice of, for example, reading a book to a child, might therefore depend on the 
contexts in which the child lives, the expectations peer-groups or families have on that child, and a myriad of additional effects that might enhance or suppress the positive effects of parenting styles, practices, or investments. Therefore, other factors affected by SES, such as neighborhoods (Minh et al. 2017), or time and stress, might, in turn, affect or even mediate the effects that the different parenting dimensions exert on one another, in some cases compensating for lack of parenting reading time, for example, while in others exacerbating its detrimental effects. This leads me to consider that the parenting literature suggests an exploration of heterogeneity; that this is warranted and necessary to understand the mediating role of parenting.

\section{Current Study}

In this paper, I explore both the causal mediated effect of parenting of the overall SES effect and heterogeneity effects on one of the parenting dimensions. To start though, first, a more broad conception of SES that is more compatible with the main theoretical claims linking SES to parenting seems necessary (Conger, Conger, and Martin 2010), especially so if interest is on showing heterogeneity and better accounting for the complexity that qualitative studies point to. I make use of Latent Class Analysis (LCA) to group parents according to the position they occupy in the social structure in terms of educational levels and occupational attainment of both the mother and father of the child, the household income, and household net-wealth levels, and whether parents receive welfare. This social position is assumed to be unobservable, but it may be possible to better approximate it without reducing the concept of SES to the educational attainment levels of one parent. Although that is how most of 
the literature conceptualizes SES, a multidimensional characterization of parental SES seems more attuned to the arguments around parenting effects that cannot, in any case, be reduced to mothers' educational attainment.

Second, the paper focuses on the extent to which parenting mediates the effects of this more encompassing measure of SES on children's language skills through the estimation of the mediated share of the total effect (TE) and the natural indirect effect (NIE), $s=N I E / T E$. Parenting should encompass parenting practices $M^{P}$, parenting styles $M^{S}$, and parental investments $M^{I}$, as in $M=\left(M^{P}, M^{S}, M^{I}\right)$. Given that previous studies suggest these are positively associated with language development, it is hypothesized that parenting mediates close to all of, or at least the major part of, the SES effects on language skills. Although these multiple though distinct parenting dimensions can be thought of as mediators, studies suggest strong interactions with one another, something which should be considered in estimations of the mediated share. Not only that, but parenting is itself a function of multiple factors beyond SES, and these have to be considered simultaneously when estimating its effects and on the estimation of the mediated share. For example, children from low-SES backgrounds may spend more time with their mothers, yet the time-intensive parenting with low-educated mothers may not be as effective in the teaching of language skills, especially if the motherchild interaction does not correspond to a sensitive parenting style. Dual-earner families, in which both parents work full-time, may have less time to engage in highly intensive parenting practices, but full-time work, especially in high paying occupations, may also allow families to purchase time-intensive activities for their children or higher quality childcare. Given those interactions, there is reason to doubt parenting would mediate close to the full share 
of the SES total effect (Milkie, Nomaguchi, and Denny 2015; Sullivan, Ketende, and Joshi 2013), Therefore, an estimation of the mediated share of the SES effect that goes through parenting requires a particular kind of causal mediation analysis that accounts for exposure induced mediator-outcome confounding and mediator-mediator effects (VanderWeele and Vansteelandt 2014).

And third, the paper considers that potential parenting dimensions may not have the same effect on all children and that, therefore, there is room to consider whether parenting effects may be heterogeneous, something which may additionally help in explaining why parenting may not fully mediate the effects of SES. This exploration of heterogeneity is done employing quantile regression in the estimation of causal effects. Quantile treatment effects may provide hints at a so-far unexplored form of heterogeneity in the literature. This paper addresses the potential for heterogeneity in effects on parenting practices or joint activities related to early-literacy through estimations of the effect of parenting practices on different quantiles of the language skills distribution.

\section{METHODS}

\section{Data}

This study uses data from the National Education Panel Study (doi:10.5157/NEPS:SC1: 6.0.0), a random sample of Germany-born children, a cohort of newborns in Germany that has been followed for over seven consecutive years. The data sampling was based on official register data on births that occurred between 2011 and 2012 in Germany (NEPS-SC1, 
Blossfeld, Roßbach, and Maurice 2011). NEPS data was collected as part of the Framework Program for the Promotion of Empirical Educational Research funded by the German Federal Ministry of Education and Research (BMBF). As of 2014, NEPS is carried out by the Leibniz Institute for Educational Trajectories (LIfBi) at the University of Bamberg in cooperation with a nationwide network. The sample was generated using a complex random study design and in each follow-up survey, children's characteristics, and performance in standardized tests were recorded along with parents' characteristics and their parenting. From the original sample of NEPS-SC1 $N=3418$, I excluded all children with a migration background (i.e., being second or third generation, $N=1589$ ) to arrive at a final sample of $n=1892$ children for which both parents have no migration background. Although this exclusion prevents me from exploring the topic of parenting among the Germany-born children of migrants, standardized language assessments, such as the ones used in this study, have been shown to be biased against children from minority-language homes. The language assessments used in this study are based on the German language and given that other studies have shown these assessments to be sensitive to the language spoken at home (Leśniewska, Pichette, and Béland 2018), the inclusion of children with a migration background may understate the effects of parenting, as understood in this paper, because for this population group parenting may not appear to readily translate into language development as measured in German. Therefore, in order not to confuse the minority-language background with low-skills in language, this exclusion is necessary. 


\section{Dependent variable: language skills}

Two standardized language assessments for children are used to quantify language development. First, the Parent's Questionnaire for the Early Diagnostic of Children at Risk 2 (Elternfragebogen für die Früherkennung von Risikokindern 2; ELFRA-2) was given to the child's parents when children were between 25-27 months of age. This is a standardized questionnaire containing a list of words and utterances that a child should be able to say at a given age. This questionnaire is filled in by the child's main caregiver and consists of three subscales that assess productive vocabulary, syntax, and grammatic abilities in German. The ELFRA-2 is used as a screening test for diagnosing delays in language development in German children aged 24 months (see for an overview of the test Grimm and Doil 2006), but it may serve as a first indirect assessment of language skills in early childhood. I make use of the subscale on productive language (ELFRA-2P), which consists of a list of words that the child might be able to utter at that age. Although the ELFRA-2 may be affected by response desirability bias, the scale may still serve as a rough measure of the child's vocabulary size (e.g., it resembles and has a high correlation with other more standard language assessments that are only doable on older children). The scale has been shown to have adequate reliability values according to the standards but is sensitive to the language spoken at home (Sachse and Von Suchodoletz 2007). The second assessment was the Peabody Picture Vocabulary Test Fourth Edition (PPVT-4), which was applied at waves four and six when children were between 37-39 months of age and five years of age respectively. The PPVT-4 assesses receptive vocabulary or verbal/language skills in children and adolescents in the German norm-referenced sample (Roßbach, Tietze, and Weinert 2005). The test contains 228 items 
divided into 19 sets, each containing 12 items, which were presented on a tablet displaying four different images. During the test, the child listens to a word and must then select the image illustrating the word out a choice of four images being displayed. The total number of correct responses is often used to establish the stage of children's language development.

\section{Mediators: Parenting}

Given that parenting involves multiple factors and processes, this study tries to encompass the broadest possible available set of things that parents can do with their children. The approximation to the construct of parenting style was based on a standardized motherchild play situation interaction (A. Linberg et al. 2019; Sommer and Mann 2015), which was videotaped and coded by independent raters according to how characteristic/uncharacteristic certain statements apply to the interaction seen in the video. These statements concern the sensitivity to distress and non-distress, intrusiveness, detachment, stimulation, positive regard, and emotionality. Table S1 in Supplementary Materials contains more details on how the construct of parenting style was operationalized. Given that this is an interaction situation, within this paradigm, both mother and child's behavior were rated because multiple reciprocal interactions might take place (Linberg 2018). However, only the mother's behaviors were used to approach parenting style. Different strategies have been proposed to classify parenting styles, but in this paper, a latent class analysis was used to classify the observed ratings into the theoretical three parenting styles, which have been most discussed in the literature (e.g., Berge et al. 2010). Although the dimensions sensitive and detached emerged clearly from the data, most of the mothers fell within an "average" parenting style 
that is not easily classifiable. Further analysis of the data reveals that the best fit is not consistent with three types of parenting style, but such explorations were beyond the scope of this paper.

Table 2 presents descriptive statistics for all measures of parenting used in the study. Parental investments were captured through questions regarding extra spending on activities such as participation in toddler or playgroups, baby swimming, music groups, or parent-child programs. Another form of parental investment is parental leave, and a binary indicator for whether the mother and father took parental leave during the first year of the child was considered. One other form of parental investment corresponds to parents buying or organizing childcare by other means, for example, through grandparents, childcare, nanny, au-pair, friends, etc., and this may correspond to a confounder of the effect of parenting. Therefore, a binary indicator of whether the child spends some time in any of these childcare arrangements was included. Finally, the available time spent with the child might be taken as another form of parental investment. Although time-use data is not available to estimate time spent between mother, father, and child, a potential solution was to consider the number of working hours of both mother and father at each wave. Working hours are, in any case, an important confounder of the association between parenting and language skills because working for a large number of hours would imply less available time to spend with children, and working hours are a confounder affected by SES. Similarly, one last mediating mechanism considered here corresponds to children's behavior problems as measured by the Strength and Difficulties Questionnaire (SDQ; Goodman et al. (2000)), which, although not a measure of parenting, is a potential mediator that is affected by, and which may directly affect parenting. 
This because parenting may result as a reaction to specific behaviors of the child. Such twoway interactions are more prevalent than just in this indicator, but these were not captured in the NEPS. I considered that including at least some of these might reduce bias in the estimation of the mediated share. The parenting practices scores by wave are based on the list of items detailed in Table 2 and refer to the frequency of joint activities with the child. Among these items, I included all information on activities such as reading to the child, dealing with literacy and numeracy activities, such as recognition of words, playing with the child in cognitively stimulating activities, teaching rhymes or songs, etc. These activities could have been performed by the parents or any other person in the household. This index was computed for each wave. Although these are simple additive and standardized scores, they may serve as rough approximations to the frequency with which early literacy activities take place.

\section{Latent class analysis}

Three methods form the basis of this study, the first of which, approaches the problem of measurement of SES. Because SES is an unobservable and theoretical construct (Lahire 2019; Savage et al. 2013), an inductive or formative approach seems more appropriate than the reductionist perspective that focuses on, say, mother's educational level, to approximate it, ignoring potential measurement error (i.e., educational attainment of the mother does not fully capture the construct of SES and it does so with systematic error, for example, it ignores the educational level of the father). For example, the occupation of both parents may be relevant for language development when parents work in fields such as education or 
health versus manual occupations with little involvement of verbal abilities, beyond parents' educational levels. Equally so, parents with high financial resources, but low educational attainment, may compensate for lacking educational credentials through private tutoring, or by enrolling their children into verbally intensive activities or social networks. Therefore, and although the SES-related individual variables may be used in place of a latent construct, these do not necessarily replace it and may serve as poor substitutes especially when restricted to the mother side, as often done in the literature. Adjusting for SES should be more attuned to what the concept entails, in terms of its implications for parenting and children's language development.

The underlying assumption in LCA is that the SES indicators are assumed to be conditionally independent given the latent class so that each latent class is what makes those indicators correlate with one another. If the social position is what creates an association between markers of SES, then it seems plausible to argue and interpret the latent classes as the socioeconomic position occupied by parents, the unobservable latent SES. The number of latent classes was chosen according to statistical fit criteria using the Bayesian Information Criteria (BIC). The following parental socioeconomic indicators were used in this analysis: a) the educational levels of mother and father; b) the occupations of mother and father classified by the occupational class structure of Eriksson and Goldthorpe (see Evans 1992); c) a categorized version of the monthly household adjusted income level as reported by the child's parents by quartiles; d) a categorized version of the level of net-wealth in the household by quartiles as well; and e) an indicator of whether mother or father received welfare benefits. 


\section{Causal joint mediation}

The second method concerns causal mediation analysis. Recent advances in mediation anal-

ysis have pointed out that the identification of mediating pathways relies upon untested and unrealistic assumptions (VanderWeele 2015). Previous studies seeking to understand direct and indirect effects of parenting are based on so-called "third variable analyses" ( $\mathrm{T}$. Linberg et al. 2019), like Oaxaca-Blinder decomposition methods (Nguyen, Schmid, and Stuart 2020); but also employing approaches based on structural equation models (Guo and Harris 2000). Those are, however, descriptive analyses given that they do not explicitly address potential confounding of target variables lying in the mediating pathways. In contrast to such decomposition methods, causal mediation analysis emphasizes the problems for identification. There are four main assumptions in causal mediation analysis: First, that there is no unmeasured confounding of the exposure-outcome association $Z \rightarrow Y$, which in mathematical notation can be written as $Y(z, m) \Perp Z \mid C, \forall z, m$ with $z$ being the observed level of SES and $m$ the values taken by the mediators; second, that there is no unmeasured confounding of the mediator-outcome association, $M \rightarrow Y$, or that $M(z) \Perp Z \mid C, \forall z$, where $M(z)$ is the counterfactual value of the mediators had the exposure been set to $z$ possibly contrary to fact; third, there is no unmeasured confounding between the exposure-mediator association, $Z \rightarrow M$, or that $Y(z, m) \Perp M \mid Z=z, C, \forall z, z^{*}, m$, with $z^{*}$ being another level of exposure SES different to $z$; and fourth, that there are no confounders of the mediatoroutcome association, $M \rightarrow Y$, that are affected by the exposure, that is, that they are also caused by $Z$ : $Y(z, m) \Perp M \mid Z=z, C, \forall z, z^{*}, m$. This last assumption, also known as no exposure-induced mediator-outcome confounding, can be expected not to hold for the case 
of parenting.

All major surveyed theories, the family stress model, the family investment model, and the bioecological model, so prescribe it. If SES affects some dimension of parenting that in turn affects another one, then these fourth assumption does not hold and the mediating effect of each parenting dimension is not identified. For example, research has shown sensitive mothers perform more time-intensive parenting practices with their children, and that highSES mothers adjust their parenting to fit the child's needs (Kalil, Ryan, and Corey 2012). Also, parental investments in the form of books or cognitively stimulating toys may affect how often children are exposed to literary content and stimulating activities, and through that pathway to more frequent reading or more time with sensitive mothers. Therefore, what these hypotheses point to is that parenting as a mediator is akin to a causal sequential chain, which renders the effect of single pathways unidentifiable based on the traditional mediation analysis.

Instead, an alternative approach is to consider multiple mediators 'en bloc' (VanderWeele and Vansteelandt 2014). I perform a joint mediation analysis to identify the share of the SES effect on language skills that is mediated through all the parenting mediators jointly. The total effect of the exposure $T E\left(z, z^{*}\right)=E\left(Y\left(z^{*}\right)\right)-E(Y(z))=E\left(Y\left(z^{*}, M\left(z^{*}\right)\right)-E(Y(z, M(z)))\right.$, where $Y(z, M(z)$ is a nested-counterfactual: the language score that a child exposed to SES level $z$ would have had the mediators taken the actual value corresponding to that exposure $z$. The TE can be decomposed into the natural direct effect $N D E\left(z, z^{*}\right)=E\left(Y\left(z^{*}, M(z)\right)\right)-E(Y(z, M(z)))$, and the natural indirect effect, $\operatorname{NIE}\left(z, z^{*}\right)=E\left(Y\left(z^{*}, M\left(z^{*}\right)\right)\right)-E\left(Y\left(z^{*}, M(z)\right)\right)$, which goes through the sequential 
chain $M$, that does not need to be specified in detail, and where $z$ and $z^{*}$ are the observed SES exposure and its counterfactual, $M(z)$ the values the parenting mediators would take given that SES was the value $z$, and $Y(z, M(z))$ the value of language skills that would have been observed had SES $Z=z$ and the parenting mediators taken the values they would have taken under that value of the exposure SES $z$. In this framework, $Y_{i}(0)=Y_{i}\left(0, M_{i}(0)\right)$ to $Y_{i}(1)=Y_{i}\left(1, M_{i}(1)\right)$ is akin to the value of the mediator that follows "naturally" from the exposure being from one SES level to another one. Therefore, joint mediation analysis allows for more clarity regarding these different effects. The $N D E$ is the effect of changing the exposure (say from very low-SES 0, to high-SES level 1), but fixing the parenting mediators, all jointly, that is, not letting these mediators change in response to the exposure change in SES level; whereas the the NIE is the effect of the parenting mediators switching from $M_{i}(0)$ to $M_{i}(1)$ (as if in response to a change in exposure), while the exposure SES is fixed at some level (so that there is no direct effect element). The share mediated is, thus, defined as $s=N I E / T E \times 100$ which is the quantity of interest for this paper and a potentially relevant quantity for public policy.

The mediating effect of parenting, taken as a multiple and simultaneous mediational process, can be estimated employing joint mediation analysis. The added value of this method is that it allows quantifying $s$ despite the complex confounding implied by parenting as a mediator of the SES effect. This is done by including, within the mediating pathway set, all the confounders affected by exposure (working hours, child care, behavior problems, etc.), which renders the joint effect identifiable. The joint mediation approach is a convenient solution to the problem of estimating the share of SES mediated through parenting when 
exposure-induced confounding is present, something which has not been addressed by previous studies. All variables in Table 2 are considered jointly and the goal of the analysis is to estimate their joint mediated effect: for language development at wave 3, a total of 5 mediators and confounders; for wave 4, a total of 11 mediators and confounders; and for the 6 th wave a total of 21 mediators and confounders. This has the advantage of not only adjusting for confounding when the mediators affect each other in reciprocal ways but also when there remain unobserved confounders of these mediators that are shared by more than one mediator in the causal chain such as parents' personality or cognitive abilities, the neighborhoods children live in, etc. (VanderWeele and Vansteelandt 2014; Steen et al. 2017). The $N D E$ and the NIE were estimated by the imputation-based approach and a series of linear regression models for the associations between exposure, mediator, and outcome variables, as explained in (Steen et al. 2017), in which all mediators lying in the causal pathway, as well as interactions between SES and the mediators, were considered. The main drawback of this approach, as well as the traditional mediation method, is that it is no longer possible to identify specific pathways without making strong assumptions that seem unlikely to hold for the case of parenting.

\section{Quantile regression}

The third method, in turn, addresses one potential source of heterogeneity in the effects of parenting, through a more detailed look at one of its dimensions. Heterogeneous effects for the parenting practices score $M^{P}$ were obtained employing quantile regression (Koenker

2012). The parenting practices score $M^{P}$ may serve as an indicator of the intensity of 
parenting activities associated with early literacy skills, but a similar analysis could be performed on each of the parenting mediating processes and variables. One of the advantages of quantile regression is that the effects of parenting on the language skills of children can be estimated on the conditional median and other quantiles of the response variable. Estimating rates of change along the distribution of the language skill indicators is useful because parenting may have differential effects on the language skill's mean and variance across the distribution, especially when hidden confounding variables might remain unobserved in the model. Interest is on estimating the effects of the mediator parenting practices on language development as measured at multiple timepoints, $M_{t-1}^{P} \rightarrow Y_{t}$. To accomplish this, while simulateneously adjusting for confounding, quantile regression estimates are adjusted by all past mediators of parenting style $M_{t-2}^{S}$ and parental investments $M_{t-2}^{I}$, the time-invariant confounder covariates $C$, and the previous scores on language skill $Y_{t-1}$. Given $Q_{y}(\tau \mid Z)$, the inverse of the conditional cumulative distribution function of the response variable $Y$, $F_{y}^{-1}(\tau \mid Z)$, where $\tau \in[0.05,0.10,0.15,0.20, \ldots, 0.95]$ denoting the quantiles at which the effect is estimated. Estimates of the quantile treatment effect can be interpreted as rates of change conditional on the effects of covariates for a specific quantile. These are expected to vary given that there is heterogeneity in these effects.

Finally, Table S2 in Supplementary Materials presents the definition and descriptive statistics for all adjustment variables and confounders of the exposure-outcome and mediator-outcome associations including, though not limited to, gender, birth order, premature, low birth weight, smoking or drinking while pregnant, etc. A further discussion of the coefficients associated with those variables is not warranted by these analyses and is therefore excluded 
from the paper. All estimates, both the joint mediation and the quantile regression analyses, are adjusted by these variables.

\section{Missing data and panel attrition}

Missing data and systematic panel attrition may generate bias in the estimates of interest in this paper. To deal with these two issues, multiple imputation by chained equations with 56 imputed data sets was performed (Young and Johnson 2015) The method CART was used to impute missing values because it has been shown to ensure the best possible predictions within the observed value range of each variable (Burgette and Reiter 2010). All analytical variables were used in the multiple imputation procedure. After converting the data into wide format, all variables observed at time point $t-1$ served as predictors for the missing values at $t$, and subsequently those from $t-1$ and $t$ were used as predictors for the missing values at $t+1$, excluding observations lost to follow-up did not affect the findings. No noticeable convergence issues were observed in the resulting multiply imputed values.

\section{FINDINGS}

Table 1 shows the classification of SES into four strata, which was chosen as providing the best fit based on the lowest BIC. This classification suggests SES can be grouped into very low-, low-, medium-, and high-SES latent classes. The high-SES class is composed of fathers and mothers with a high educational level and occupational attainment, most

of them in the highest two categories of the EGP scheme; these parents are also in the 
highest income and net-wealth categories, and none of them receives welfare. The very lowSES group, at the other extreme, is composed of parents with the lowest educational and worst occupational attainments (mostly IIIb, V, VI, VIIa, and VIIb for fathers, and mostly IIIa, IIIb, V, VI, VIIa, and VIIb for mothers). These very low-SES parents are mostly in the lower-income and lower-net-wealth brackets (e.g., including negative net-wealth), and a majority of them are welfare recipients. On the middle range, the categories low- and medium-SES are also distinguished from these two extremes. Although the medium-SES category also has high educational and occupational attainments, of a similar level to the high-SES class, their income and net-wealth levels are, on average, lower than the levels of the high-SES parents. This suggests that the LCA separated the group of highly educated parents with high economic and financial resources from the highly educated parents with lower financial resources, something that would have been neglected had we looked at a single education dimension. Regarding the low-SES latent class, this one differs from both the very low- and medium-SES by their relatively higher income levels, but generally lower educational levels, respectively. In terms of occupational attainment, the low-SES group is composed of a large group of technical/applied or civil servant workers, especially fathers, but a higher percentage of mothers who are out of the labor force compared to any of the other socioeconomic groups. The LCA, therefore, yielded a gradational classification of parents that combines the information of mothers and fathers (e.g., a gradient in the language gap is much clearly observed when considering these four latent classes than the more traditional measure of mother's educational level; these results are available upon request).

Table 2 shows the distribution of all mediators considered, as well as the exposure-induced 
confounders of the mediator-outcome relation that should also be included within the computation of the joint mediation effect. In accordance with previous studies, parents in the high-SES group have, on average, higher levels of parental investment, more frequent parenting practices, and a slightly higher presence of sensitive mothers than parents in the very low- and low-SES groups. The exposure-induced confounders are also strongly stratified by SES. In terms of number of hours, high-SES parents have the highest number, but they also tend to take parental leave and invest in child care arrangements, especially when compared with the very Low-SES group of parents. Overall, one can observe a strong gradient in all these different constructs, which constitutes evidence in support of the parenting deficits perspective.

Regardless of the parenting dimension that is considered, substantial differences in parenting can be observed in this cohort, as shown in Table 2. Children from very low-SES backgrounds are, on average, less frequently exposed to parenting practices that promote reading, and more exposed to less sensitive mothers, than their high-SES peers. In terms of working hours, parents from high-SES backgrounds report, on average, to work for longer than their lowSES background peers, which would suggest that the differences in parenting time are larger among high-SES children. However, children from very low- and low-SES lag behind their high-SES background peers in terms of parental investments, and significantly on childcare, as seen in the percentage of children cared for by others at each wave. Behavior problems are also higher among children from very low- and low-SES families.

Figure 1 shows the size of the NIE and the NDE stacked on top of each other for the counterfactual reference group of being a high-SES child. The height of the bar corresponds 
to the $T E$, which is the effect on the language skills of very low-SES had children been raised in high-SES family environments instead of the ones they were raised in. These are all substantial large effects, as found in (Skopek and Passaretta 2020). Results show the well-known finding that children from very low-SES families are the furthest away from the high-SES group. The share $s$ on the plots, which can only be computed when both the direct and indirect effects point in the same direction, is the estimate of the mediated share of the SES effect which goes through parenting, which is higher for children from very low SES, implying that differences in parenting are more consequential for these children. When children were between 24-27 months of age, this share is, however, lower than the estimated share when children reached 35-39 months of age, and lower than when they reached 5 years old.

Figure 2 shows the quantile effects of parenting practices at different time points on the three measures of language skills or verbal abilities and a dashed-line for the adjusted average effect. Estimates of the quantile treatment effect can be interpreted as rates of change conditional on the effects of covariates for a specific quantile. In that sense, results suggest that parenting practices are less effective for certain children than for others, which would make interventions on parenting less effective overall when such differences are not accounted for, as shown in the deviation of the curves from the average effect illustrated by the dashed horizontal lines. Moreover, a left-to-right reading of Figure 2 reveals the well-known fact that earlier interventions have larger impacts on language than later ones; whereas a topto-bottom view of each panel in Figure 2 suggests a trend for the accumulation of effects. The effect of early parenting practices at 24-27 months of age evaluated on the language 
skills of five-year-olds are larger than the effects of parenting practices when children were 35-39 months old, or 4, or even 5 years old. These results suggest that the effectiveness of parenting practices might decrease over time, as children age, which is related to fade-out effects seen in early childhood intervention studies (Duncan, ZiolGuest, and Kalil 2010). The larger effects of earlier parenting practices tend to vanish in terms of their impact on later scores of language development. However, Figure 2 also shows that there is a considerable degree of heterogeneity in these effects. Children below the median of the distribution tend to be the most positively affected by parenting practices, at least more than average (i.e. higher than the corresponding dashed-lines), which suggests that there is a great potential for interventions geared at increasing the reading time/frequency of parents to children. Children at the 10th or lower percentiles of the distribution of language skills, however, as well as the children at the 90th or higher percentiles, show the smallest effects, though potentially for very different reasons. This may also correspond to floor or ceiling effects, for example. However, an alternative interpretation suggests parenting practices would have little effect in reducing gaps between the least verbally developed and the most verbally developed children.

\section{DISCUSSION}

Overall, results suggest parenting mediates an important share of the effect of SES on the language skills of preschool children. Children from very low-SES are the furthest apart from the high-SES children, but the earliest gaps among these two groups are the least affected by parenting. The fact that the share of the joint parenting mediators reaches at 
most approximately one-half of the total effect of SES on children's language skills strongly suggests that other pathways might be causing these inequalities, pathways which would not be addressed by interventions on parenting. Furthermore, there is heterogeneity in the effects of the parenting practices, which suggests heterogeneity on other parenting mediators as well. Although parenting practices would have a positive effect on language abilities, thus reducing social inequalities, the effects might be heterogeneous and they might fade-out as children age, suggesting that interventions sustained over time would be crucially needed.

This paper contributes to the increasing breadth of evidence documenting social inequalities in language skills among pre-school children by parents' SES. Results suggest that, although social inequalities in language can be found from early on, contrary to expected, parenting, 'en bloc', does not act as the main mediating mechanism generating them when comparing children at different ages. Although a large chunk of the effect of SES on the children's language development is mediated, in one way or another, through parenting, a sizeable share of the SES effect operates through alternative pathways. Seemingly though, these alternative mechanisms do not operate through parenting and therefore would not be subject to "improvements" in the parenting skills, styles, practices, or parental investments of low-SES parents, as could be inferred from the studies of Milkie, Nomaguchi, and Denny (2015) and Sullivan, Ketende, and Joshi (2013). Therefore, language skills in children would remain to be stratified by SES, even when parenting gaps are closed. Moreover, interventions on parenting practices may have positive effects in increasing language skills in children, but their impact is heterogeneous and would tend to affect the least those who are the furthest behind in terms of language skills, which are presumably the group needing such interventions the 
most. Given that those are the children for which the differences in parenting are the largest, we can indirectly infer that intervening in parenting practices might not be as effective in reducing the largest gaps. Results of this paper also suggest that these heterogeneous effects might fade-out over time, and that, therefore, a substantial reduction in social inequalities in language skills would not necessarily follow from single time point interventions on parenting practices, and would required sustained efforts. Thus, these results show that inequalities in language skills are not simply the product of deficits in parenting.

This paper highlights various avenues for future research on the effects of parenting and its often unaddressed limitations and provides three main contributions to the literature on SES, parenting, and language development of children. First, the paper presents a more appropriate measure of SES that attends to the potential for confounding and measurement error in individual unidimensional indicators and appropriately incorporates both parents' characteristics. This certainly helps to reveal the important effects of a complex construct such as SES. Second, it is surprising that the mediated share of the joint effects of parenting is not higher than what was found in this study, especially given the number of mediators considered, and the number of potential pathways that are being simultaneously examined. However, previous studies had not quantified this share and, to my knowledge, this is the first study to do so. Third, this paper also shows how some of those individual pathways, namely parenting practices related to the promotion of early literacy, may have heterogeneous effects, something that is rarely considered in the literature on parenting.

Some limitations of this paper are, however, worth noticing. In contrast to time-use studies on parenting, in this paper, I am unable to quantify the exact time that parents spend with 
children. The focus here was, however, on activities that parents do with their children, as well as their reported frequency. This limits the extent to which parenting is being captured by the indicators in the study, but it may highlight aspects of parenting that are not quantified when employing time use data. For example, I have shown that besides parenting, social inequalities exist in each of the parenting dimensions examined (available upon request) and that such differences, beyond time-use only, also explain SES related gaps. Despite this, the share of SES effects mediated through parenting remains less than what would be expected according to the theory, especially when including such a large number of mediating mechanisms or processes. One reason this may be the case is that the mediators are measured with error, something that should be addressed considering other studies with different measures, perhaps with additional time-use data. Relatedly, this paper was unable to assess the quality of the time spent in the joint activities that compose the parenting practices score, which may affect the mediated share, again, through measurement error. These can, however, be hypothesized to vary substantially between parents, even of the same SES, which might correspond to an alternative explanation for the heterogeneity in the effects observed in this paper. Finally, a rather unexplored aspect of social inequalities in language development is inequalities by children's migration background. This topic certainly deserves more attention, however, it is challenging to study language inequalities in children'S SES and migration background, when language assessments are sensitive to the language spoken at home.

Overall, the results of this paper suggest that a reduction in the parenting "deficits" of very low and low-SES parents is unlikely to make the language gaps by SES in early childhood dis- 
appear, even though these interventions might reduce some of them. Unless the unmediated share is addressed, the gaps will persist through other pathways not affected by parenting (Manstead 2018). Therefore, for the case of language skills, it would seem that environmental interventions in combination with interventions in parenting might be more appropriate to truly reduce inequalities by SES, moving public policy beyond a deficit perspective on parenting, which seems unaware of the very limited impact that psychology-based interventions would have in overcoming social inequalities. Previous studies on parenting as a mediating mechanism have not been able to identify the mediated share corresponding to specific mediating pathways, potentially involving multiple parenting dimensions. This because of the difficult to meet assumptions of causal mediation. This paper highlights the potential for extending the purview beyond parenting which, although important and consequential for language development as shown here, may not suffice. 


\section{REFERENCES}

Ayoub, Catherine, Claire D Vallotton, and Ann M Mastergeorge. 2011. "Developmental Pathways to Integrated Social Skills: The Roles of Parenting and Early Intervention." Child Development 82 (2). Wiley Online Library: 583-600.

Baumrind, Diana. 2005. "Patterns of Parental Authority and Adolescent Autonomy." New Directions for Child and Adolescent Development 2005 (108). Wiley Online Library: 61-69.

Berge, Jerica M, Melanie Wall, Katherine W Bauer, and Dianne Neumark-Sztainer. 2010. "Parenting Characteristics in the Home Environment and Adolescent Overweight: A Latent Class Analysis." Obesity 18 (4). Wiley Online Library: 818-25.

Blossfeld, Hans-Peter, Hans-Günther Roßbach, and Jutta von Maurice. 2011. "Education as a Lifelong Process - the German National Educational Panel Study (Neps)." Zeitschrift Für Erziehungswissenschaft 14 (2): 19-34. doi:10.1007/s11618-011-0179-2.

Bradley, Robert H, and Robert F Corwyn. 2002. "Socioeconomic Status and Child Development." Annual Review of Psychology 53 (1). Annual Reviews 4139 El Camino Way, PO Box 10139, Palo Alto, CA 94303-0139, USA: 371-99.

Bronfenbrenner, Urie, and Pamela A Morris. 2007. "The Bioecological Model of Human Development." Handbook of Child Psychology 1. Wiley Online Library.

Burgette, Lane F, and Jerome P Reiter. 2010. "Multiple Imputation for Missing Data via Sequential Regression Trees." American Journal of Epidemiology 172 (9). Oxford University Press: 1070-6. doi:10.1093/aje/kwq260. 
Chan, Tak Wing, and Anita Koo. 2011. "Parenting Style and Youth Outcomes in the Uk." European Sociological Review 27 (3). Oxford University Press: 385-99.

Cobb-Clark, Deborah A, Nicolas Salamanca, and Anna Zhu. 2019. "Parenting Style as an Investment in Human Development." Journal of Population Economics 32 (4). Springer: $1315-52$.

Conger, Rand D, Katherine J Conger, and Monica J Martin. 2010. "Socioeconomic Status, Family Processes, and Individual Development." Journal of Marriage and Family 72 (3). Wiley Online Library: 685-704.

Doepke, Matthias, Giuseppe Sorrenti, and Fabrizio Zilibotti. 2019. "The Economics of Parenting." Annual Review of Economics 11. Annual Reviews: 55-84.

Duncan, Greg J, W Jean Yeung, Jeanne Brooks-Gunn, and Judith R Smith. 1998. "How Much Does Childhood Poverty Affect the Life Chances of Children?" American Sociological Review. JSTOR, 406-23.

Duncan, Greg J., Kathleen M. ZiolGuest, and Ariel Kalil. 2010. "Early-Childhood Poverty and Adult Attainment, Behavior, and Health." Child Development 81 (1). Wiley Online Library: 306-25. doi:10.1111/j.1467-8624.2009.01396.x.

Duncan, Greg, Katherine Magnuson, Richard Murnane, and Elizabeth Votruba-Drzal. 2019. "Income Inequality and the Well-Being of American Families." Family Relations 68 (3). Wiley Online Library: 313-25.

Elliott, Sinikka, and Sarah Bowen. 2018. "Defending Motherhood: Morality, Responsibility, and Double Binds in Feeding Children." Journal of Marriage and Family 80 (2). Wiley 
Online Library: 499-520.

Evans, Geoffrey. 1992. "Testing the Validity of the Goldthorpe Class Schema." European Sociological Review 8 (3). Oxford University Press: 211-32. doi:10.1093/oxfordjournals.esr.a036638.

Fomby, Paula, and Kelly Musick. 2018. "Mothers' Time, the Parenting Package, and Links to Healthy Child Development." Journal of Marriage and Family 80 (1). Wiley Online Library: $166-81$.

Goodman, Robert, Tamsin Ford, Helen Simmons, Rebecca Gatward, and Howart Meltzer. 2000. "Using the Strengths and Difficulties Questionnaire (Sdq) to Screen for Child Psychiatric Disorders in a Community Sample." The British Journal of Psychiatry 177 (6). Cambridge University Press: 534-39.

Grimm, H., and H. Doil. 2006. "ELFRA 2-Elternfragebogen Für Zweijährige Kinder." Göttingen: Hogrefe.

Grusec, Joan E. 2011. "Socialization Processes in the Family: Social and Emotional Development." Annual Review of Psychology 62. Annual Reviews: 243-69.

Guo, Guang, and Kathleen Mullan Harris. 2000. "The Mechanisms Mediating the Effects of Poverty on Children's Intellectual Development." Demography 37 (4). Springer: 431-47.

Heckman, James, M Holland, K Makino, D Olds, Rodrigo Pinto, and Maria Rosales-Rueda. 2014. "The Nurse Family Partnership Program: A Reanalysis of the Memphis Randomized Controlled Trial." University of Chicago Working Paper, ed (June 1, 2014).

Heckman, James J., John Eric Humphries, and Tim Kautz, eds. 2014. The Myth of Achievement Tests: The Ged and the Role of Character in American Life. Chicago: University 
of Chicago Press.

Hoff, Erika. 2013. "Interpreting the Early Language Trajectories of Children from Low-Ses and Language Minority Homes: Implications for Closing Achievement Gaps." Developmental Psychology 49 (1). American Psychological Association: 4.

Ishizuka, Patrick. 2019. "Social Class, Gender, and Contemporary Parenting Standards in the United States: Evidence from a National Survey Experiment." Social Forces 98 (1). Narnia: 31-58.

Kalil, Ariel, and Susan E Mayer. 2016. "Understanding the Importance of Parental Time with Children: Comment on Milkie, Nomaguchi, and Denny (2015).” Journal of Marriage and Family 78 (1). Blackwell Publishing Ltd.: 262.

Kalil, Ariel, Rebecca Ryan, and Elise Chor. 2014. "Time Investments in Children Across Family Structures." The ANNALS of the American Academy of Political and Social Science 654 (1). Sage Publications Sage CA: Los Angeles, CA: 150-68.

Kalil, Ariel, Rebecca Ryan, and Michael Corey. 2012. "Diverging Destinies: Maternal Education and the Developmental Gradient in Time with Children." Demography 49 (4). Springer: 1361-83. doi:10.1007/s13524-012-0129-5.

Koenker, Roger. 2012. "Quantile Regression in R: A Vignette." Retrieved November.

Kuppens, Sofie, and Eva Ceulemans. 2019. "Parenting Styles: A Closer Look at a WellKnown Concept." Journal of Child and Family Studies 28 (1). Springer: 168-81.

Lahire, Bernard. 2019. Enfance de Classe. Seuil.

Lareau, Annette. 2011. Unequal Childhoods: Class, Race, and Family Life. Univ of Califor- 
nia Press.

Leśniewska, Justyna, François Pichette, and Sébastien Béland. 2018. "First Language Test Bias? Comparing French-Speaking and Polish-Speaking Participants' Performance on the Peabody Picture Vocabulary Test." Canadian Modern Language Review 74 (1). University of Toronto Press: 27-52.

Linberg, Anja. 2018. Interaktion Zwischen Mutter Und Kind: Dimensionen, Bedingungen Und Effekte. Waxmann Verlag.

Linberg, Anja, Daniel Mann, Manja Attig, Franziska Vogel, Sabine Weinert, and HansGünther Roßbach. 2019. "ASSESSMENT of Interactions with the Macro-Analytic Rating System of Parent-Child-Interactions in the Neps at the Child'S Age of 7, 17, and 26 Months."

Linberg, Tobias, Thorsten Schneider, Jane Waldfogel, and Yi Wang. 2019. "Socioeconomic Status Gaps in Child Cognitive Development in Germany and the United States." Social Science Research 79: 1-31.

Maccoby, Eleanor E. 2000. "Parenting and Its Effects on Children: On Reading and Misreading Behavior Genetics." Annual Review of Psychology 51 (1). Annual Reviews 4139 El Camino Way, PO Box 10139, Palo Alto, CA 94303-0139, USA: 1-27.

Madigan, Sheri, Heather Prime, Susan A Graham, Michelle Rodrigues, Nina Anderson, Jennifer Khoury, and Jennifer M Jenkins. 2019. "Parenting Behavior and Child Language: A Meta-Analysis." Pediatrics 144 (4). Am Acad Pediatrics: e20183556.

Manstead, Antony SR. 2018. "The Psychology of Social Class: How Socioeconomic Status 
Impacts Thought, Feelings, and Behaviour." British Journal of Social Psychology 57 (2). Wiley Online Library: 267-91.

Mayer, Susan E, Ariel Kalil, Philip Oreopoulos, and Sebastian Gallegos. 2019. "Using Behavioral Insights to Increase Parental Engagement the Parents and Children Together Intervention." Journal of Human Resources 54 (4). University of Wisconsin Press: 900925.

Melhuish, Edward C, Mai B Phan, Kathy Sylva, Pam Sammons, Iram Siraj-Blatchford, and Brenda Taggart. 2008. "Effects of the Home Learning Environment and Preschool Center Experience Upon Literacy and Numeracy Development in Early Primary School." Journal of Social Issues 64 (1). Wiley Online Library: 95-114.

Milkie, Melissa A, Kei M Nomaguchi, and Kathleen E Denny. 2015. "Does the Amount of Time Mothers Spend with Children or Adolescents Matter?" Journal of Marriage and Family 77 (2). Wiley Online Library: 355-72.

Milkie, Melissa A, Sara B Raley, and Suzanne M Bianchi. 2009. "Taking on the Second Shift: Time Allocations and Time Pressures of Us Parents with Preschoolers." Social Forces 88 (2). The University of North Carolina Press: 487-517.

Miller, Daniel P, Margaret MC Thomas, Maureen R Waller, Lenna Nepomnyaschy, and Allison D Emory. 2020. "Father Involvement and Socioeconomic Disparities in Child Academic Outcomes." Journal of Marriage and Family 82 (2). Wiley Online Library: $515-33$.

Millet, Mathias, and Jean-Claude Croizet. 2016. L'école Des Incapables? La Maternelle, 
Un Apprentissage de La Domination. Paris: La Dispute.

Minh, Anita, Nazeem Muhajarine, Magdalena Janus, Marni Brownell, and Martin Guhn. 2017. "A Review of Neighborhood Effects and Early Child Development: How, Where, and for Whom, Do Neighborhoods Matter?" Health \&f Place 46. Elsevier: 155-74.

Mollborn, Stefanie. 2016. "Young Children's Developmental Ecologies and Kindergarten Readiness." Demography 53 (6). Springer: 1853-82.

Nguyen, Trang Quynh, Ian Schmid, and Elizabeth A Stuart. 2020. "Clarifying Causal Mediation Analysis for the Applied Researcher: Defining Effects Based on What We Want to Learn." Psychological Methods. American Psychological Association.

Nomaguchi, Kei, Melissa A Milkie, and Kathleen E Denny. 2016. "Quantity of Maternal Time and Child and Adolescent Development: Response to Kalil and Mayer (2016) and to Waldfogel (2016)." Journal of Marriage and Family 78 (1). Blackwell Publishing Ltd.: 269.

Price, Joseph. 2010. "The Effect of Parental Time Investments: Evidence from Natural Within-Family Variation." Unpublished Manuscript, Brigham Young University.

Romeo, Rachel R, Julia A Leonard, Sydney T Robinson, Martin R West, Allyson P Mackey, Meredith L Rowe, and John DE Gabrieli. 2018. "Beyond the 30-Million-Word Gap: Children's Conversational Exposure Is Associated with Language-Related Brain Function." Psychological Science 29 (5). Sage Publications Sage CA: Los Angeles, CA: 700-710.

Roßbach, Hans-Günther, W. Tietze, and Sabine Weinert. 2005. Peabody Picture Vocabulary Test-Revised. Deutsche Forschungsversion Des Tests von Lm Dunn \&6 Lm Dunn von 
1981. Bamberg/Berlin: Pearson.

Sachse, S., and W. Von Suchodoletz. 2007. "Diagnostische Zuverlässigkeit Einer Kurzversion Des Elternfragebogens Elfra-2 Zur Früherkennung von Sprachentwicklungsverzögerungen." Klinische Pädiatrie 219. Georg Thieme Verlag KG Stuttgart New York: 76-81. doi:10.1055/s-2006-942174.

Savage, Mike, Fiona Devine, Niall Cunningham, Mark Taylor, Li Yaojun, Johs Hjellbrekke, Brigitte. Le Le Roux, Sam Friedman, and Andrew Miles. 2013. "A New Model of Social Class? Findings from the Bbc's Great British Class Survey Experiment." Sociology 47 (2). Sage Publications Sage UK: London, England: 219-50. doi:10.1177/0038038513481128.

Schober, Pia, and Christian Schmitt. 2017. "Day-Care Availability, Maternal Employment and Satisfaction of Parents: Evidence from Cultural and Policy Variations in Germany." Journal of European Social Policy 27 (5). SAGE Publications Sage UK: London, England: $433-46$.

Skopek, Jan, and Giampiero Passaretta. 2020. "Socioeconomic Inequality in Children's Achievement from Infancy to Adolescence: The Case of Germany." Social Forces.

Sommer, Anja, and Daniel Mann. 2015. "Qualität Elterlichen Interaktionsverhaltens: Erfassung von Interaktionen Mithilfe Der Eltern-Kind-Interaktions Einschätzskala Im Nationalen Bildungspanel." Leibniz-Institut Für Bildungsverläufe, Nationales Bildungspanel. Bamberg.

Steen, Johan, Tom Loeys, Beatrijs Moerkerke, and Stijn Vansteelandt. 2017. "Medflex: An R Package for Flexible Mediation Analysis Using Natural Effect Models." Journal of 
Statistical Software 76 (11). JOURNAL STATISTICAL SOFTWARE.

Sullivan, Alice, Sosthenes Ketende, and Heather Joshi. 2013. "Social Class and Inequalities in Early Cognitive Scores." Sociology 47 (6). Sage Publications Sage UK: London, England: $1187-1206$.

VanderWeele, Tyler. 2015. Explanation in Causal Inference: Methods for Mediation and Interaction. Oxford University Press.

VanderWeele, Tyler, and Stijn Vansteelandt. 2014. "Mediation Analysis with Multiple Mediators." Epidemiologic Methods 2 (1). De Gruyter: 95-115.

Waldfogel, Jane. 2016. "How Important Is Parental Time? It Depends: Comment on Milkie, Nomaguchi, and Denny (2015)." Journal of Marriage and Family 78 (1). Blackwell Publishing Ltd.: 266.

Young, Rebekah, and David R Johnson. 2015. "Handling Missing Values in Longitudinal Panel Data with Multiple Imputation.” Journal of Marriage and Family 77 (1). Wiley Online Library: 277-94. 


\section{TABLES AND FIGURES}

Table 1: Composition of Socioeconomic Status Latent Classes by Mothers and Fathers' Characteristics, NEPS SC1

\begin{tabular}{|c|c|c|c|c|c|}
\hline & \multirow{2}{*}{$\frac{\text { All }}{\mathrm{n}(\%)}$} & \multicolumn{4}{|c|}{ Socioeconomic Status Latent Classes } \\
\hline & & Very Low $(\mathrm{N}=221)$ & Low $(\mathrm{N}=553)$ & Medium $(\mathrm{N}=261)$ & High $(\mathrm{N}=857)$ \\
\hline \multicolumn{6}{|l|}{ Mother's educational level } \\
\hline No degree or vocational/voluntary degree & $116(6)$ & $93(42)$ & $22(4)$ & $0(0)$ & $1(0)$ \\
\hline Technical/applied or Civil Servant & $448(24)$ & $101(46)$ & $263(48)$ & $21(8)$ & $63(7)$ \\
\hline Technical Degree (Fachhochschulreife) & $528(28)$ & $25(11)$ & $247(45)$ & $61(23)$ & $195(23)$ \\
\hline University Education & $800(42)$ & $2(1)$ & $21(4)$ & $179(69)$ & $598(70)$ \\
\hline \multicolumn{6}{|l|}{ Father's educational level } \\
\hline No degree or vocational/voluntary degree & $107(6)$ & $80(36)$ & $23(4)$ & $0(0)$ & $4(0)$ \\
\hline Technical/applied or Civil Servant & $550(29)$ & $110(50)$ & $343(62)$ & $38(15)$ & $59(7)$ \\
\hline Technical Degree & $401(21)$ & $23(10)$ & $171(31)$ & $39(15)$ & $168(20)$ \\
\hline University Education & $834(44)$ & $8(4)$ & $16(3)$ & $184(70)$ & $626(73)$ \\
\hline \multicolumn{6}{|l|}{ Mother's EGP occupational class } \\
\hline I & $463(24)$ & $5(2)$ & $39(7)$ & $89(34)$ & $330(39)$ \\
\hline II & $692(37)$ & $21(10)$ & $168(30)$ & $119(46)$ & $384(45)$ \\
\hline IIIa & $210(11)$ & $78(35)$ & $87(16)$ & $12(5)$ & $33(4)$ \\
\hline IVa and IVb & $37(2)$ & $8(4)$ & $13(2)$ & $7(3)$ & $9(1)$ \\
\hline IIIb, V, VI, VIIa and VIIb & $168(9)$ & $70(32)$ & $80(14)$ & $4(2)$ & $14(2)$ \\
\hline Unemployed/OLF & $322(17)$ & $39(18)$ & $166(30)$ & $30(11)$ & $87(10)$ \\
\hline \multicolumn{6}{|l|}{ Father's EGP occupational class } \\
\hline I & $700(37)$ & $7(3)$ & $43(8)$ & $103(39)$ & $547(64)$ \\
\hline II & $505(27)$ & $18(8)$ & $123(22)$ & $101(39)$ & $263(31)$ \\
\hline IIIa & $76(4)$ & $12(5)$ & $42(8)$ & $8(3)$ & $14(2)$ \\
\hline IVa and IVb & $65(3)$ & $5(2)$ & $30(5)$ & $13(5)$ & $17(2)$ \\
\hline IIIb, V, VI, VIIa and VIIb & $531(28)$ & $172(78)$ & $312(56)$ & $31(12)$ & $16(2)$ \\
\hline Unemployed/OLF & $15(1)$ & $7(3)$ & $3(1)$ & $5(2)$ & $0(0)$ \\
\hline \multicolumn{6}{|l|}{ Household monthly income } \\
\hline$(100,1.100]$ & $362(19)$ & $210(95)$ & $76(14)$ & $74(28)$ & $2(0)$ \\
\hline$(1.100,1.550$ & $435(23)$ & $11(5)$ & $276(50)$ & $124(48)$ & $24(3)$ \\
\hline$(1.550,2.080]$ & $552(29)$ & $0(0)$ & $178(32)$ & $63(24)$ & $311(36)$ \\
\hline$(2.080,16.200]$ & $543(29)$ & $0(0)$ & $23(4)$ & $0(0)$ & $520(61)$ \\
\hline \multicolumn{6}{|l|}{ Welfare Recipient } \\
\hline Yes & $180(10)$ & $164(74)$ & $3(1)$ & $12(5)$ & $1(0)$ \\
\hline No & $1,712(90)$ & $57(26)$ & $550(99)$ & $249(95)$ & $856(100)$ \\
\hline \multicolumn{6}{|c|}{ Household net-wealth Categories in Euros } \\
\hline$(-400000,500]$ & $444(23)$ & $176(80)$ & $139(25)$ & $91(35)$ & $38(4)$ \\
\hline$(500,50 \prime 000]$ & $530(28)$ & $32(14)$ & $207(37)$ & $139(53)$ & $152(18)$ \\
\hline$\left(50000,1700^{\prime} 000\right]$ & $442(23)$ & $10(5)$ & $119(22)$ & $21(8)$ & $292(34)$ \\
\hline$\left(170 ’ 000,1500^{\prime} 000.000\right]$ & $476(25)$ & $3(1)$ & $88(16)$ & $10(4)$ & $375(44)$ \\
\hline
\end{tabular}

Note: NEPS-SC1. Own calculations. 


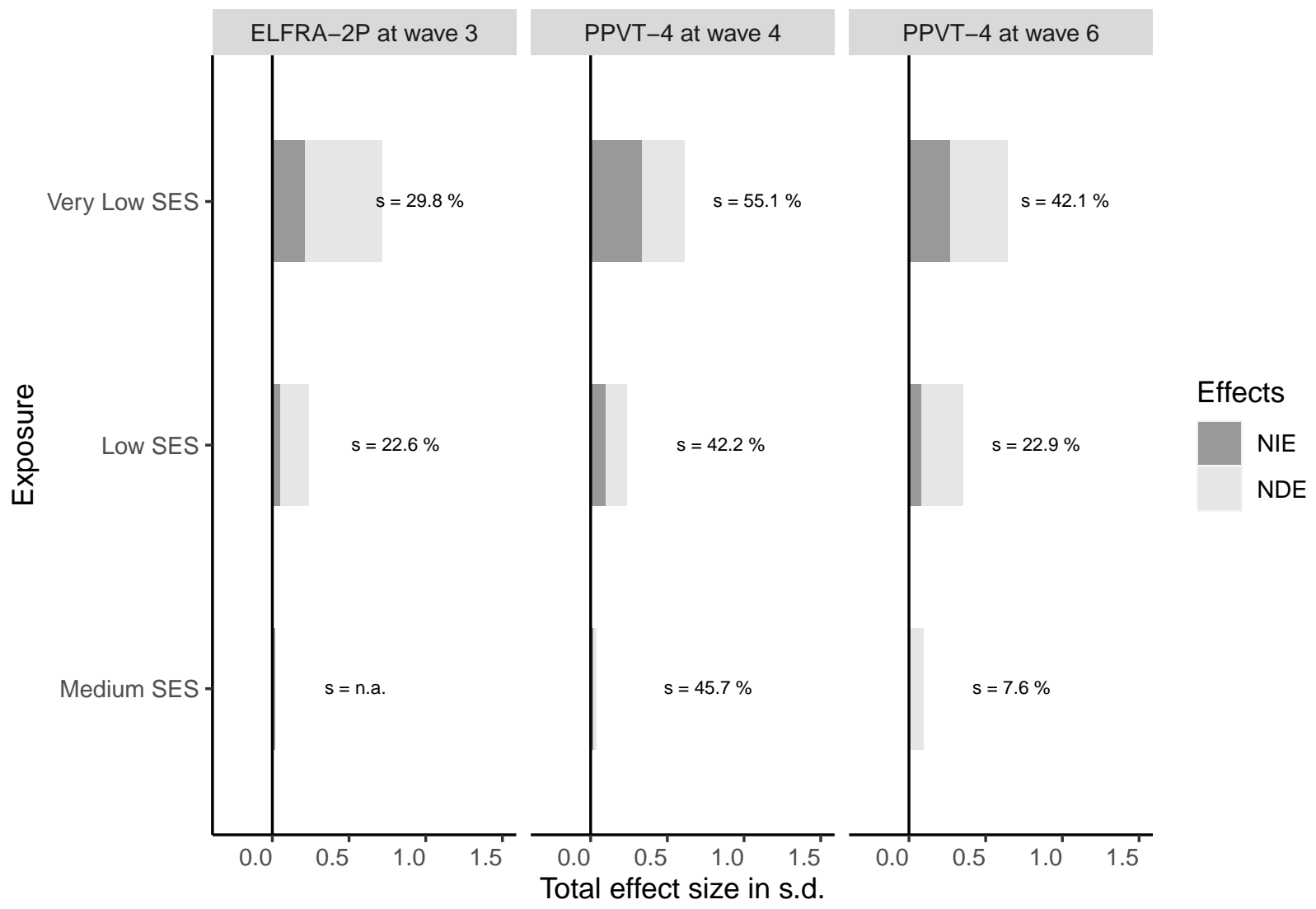

Note: NEPS-SC1, own calculations. Results adjusted by confounders in Table S2 in Supplementary Materials.

Figure 1: Joint mediation analysis showing the TE, NDE, and the NIE, as well as the share mediated by parenting 


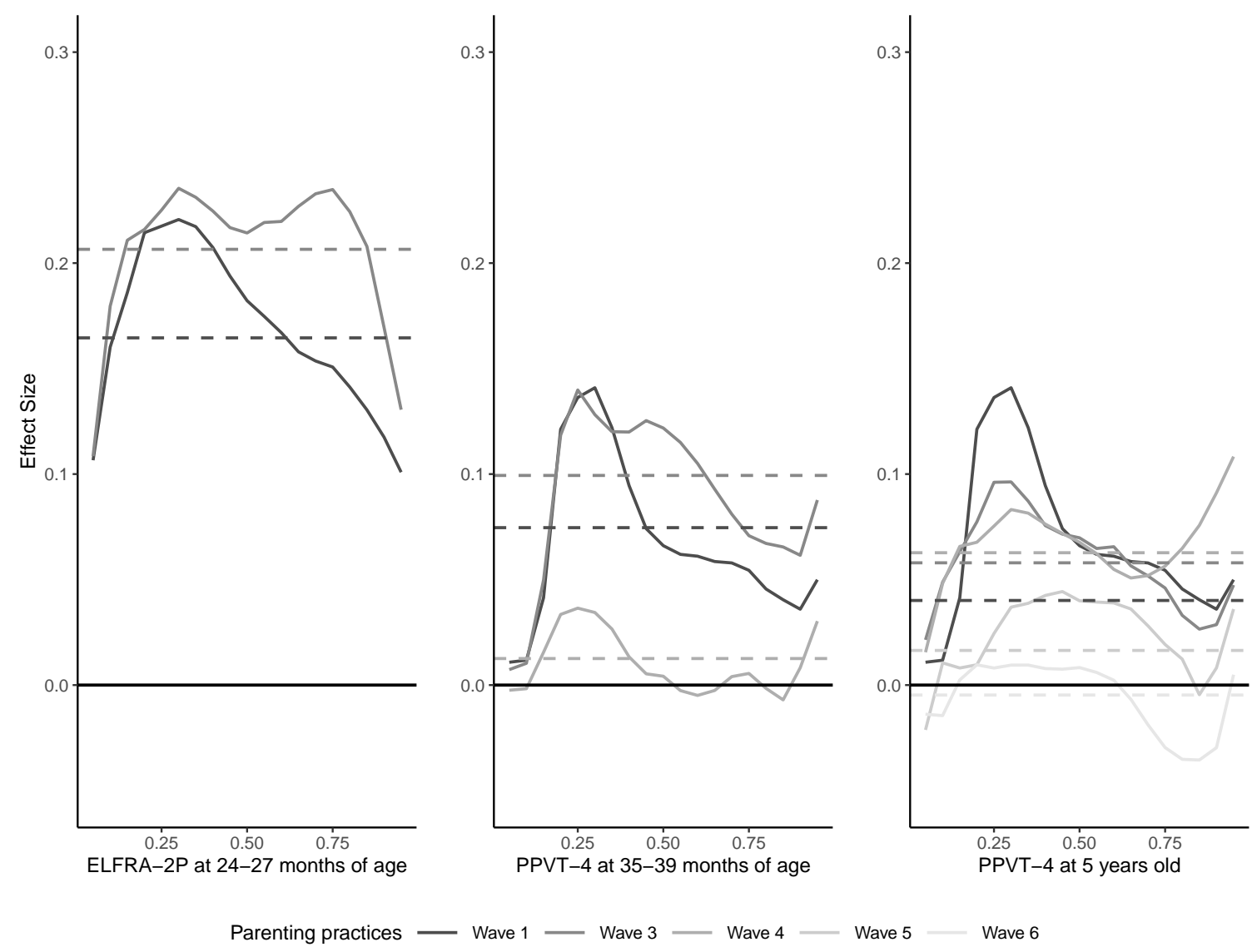

Note: NEPS-SC1. Own calculations. Results adjusted by confounders in Table S2 in Supplementary Materials.

Figure 2: Quantile regression estimates of the effect of parenting practices scores on language skills measured by the three language standardized assessments at different child ages 
Table 2: Parenting mediators and exposure-induced confounders by SES, NEPS SC1

\begin{tabular}{|c|c|c|c|c|c|c|}
\hline & \multirow{2}{*}{$\frac{\text { All }}{\mathrm{n}(\%)}$} & \multicolumn{4}{|c|}{ Socioeconomic Status Latent Classes } & \multirow[t]{2}{*}{ P-value } \\
\hline & & Very Low $(\mathrm{N}=221)$ & Low $(\mathrm{N}=553)$ & Medium $(\mathrm{N}=261)$ & $\operatorname{High}(\mathrm{N}=857)$ & \\
\hline \multicolumn{7}{|c|}{ Parenting practices score wave 1} \\
\hline Mean (sd) & $0.06(0.99)$ & $-0.19(1.05)$ & $0.01(1.00)$ & $0.03(1.01)$ & $0.16(0.95)$ & \\
\hline Median & 0 & -0.3 & 0.0 & 0.0 & 0.3 & $2.0 \mathrm{e}-05$ \\
\hline \multicolumn{7}{|c|}{ Parenting practices score wave 3} \\
\hline Mean (sd) & $-0.03(0.99)$ & $-0.24(1.17)$ & $-0.06(1.02)$ & $-0.01(0.95)$ & $0.03(0.93)$ & \\
\hline Median & 0.1 & -0.1 & 0.1 & 0.1 & 0.1 & $2.2 \mathrm{e}-02$ \\
\hline \multicolumn{7}{|c|}{ Parenting practices score wave 4} \\
\hline Mean (sd) & $0.06(0.98)$ & $-0.29(1.09)$ & $-0.01(1.02)$ & $0.12(0.88)$ & $0.18(0.92)$ & \\
\hline Median & 0.2 & -0.1 & 0.0 & 0.2 & 0.3 & $2.8 \mathrm{e}-06$ \\
\hline \multicolumn{7}{|c|}{ Parenting practices score wave 5} \\
\hline Mean (sd) & $-0.00(1.01)$ & $-0.26(1.09)$ & $-0.06(1.03)$ & $0.04(0.92)$ & $0.09(0.99)$ & \\
\hline Median & 0 & -0.2 & 0.0 & 0.2 & 0.2 & $1.9 \mathrm{e}-03$ \\
\hline \multicolumn{7}{|c|}{ Parenting practices score wave 6} \\
\hline Mean (sd) & $0.07(0.95)$ & $-0.47(1.14)$ & $0.01(0.94)$ & $0.22(0.92)$ & $0.21(0.86)$ & \\
\hline Median & 0.2 & -0.4 & 0.2 & 0.3 & 0.3 & $3.4 \mathrm{e}-10$ \\
\hline \multicolumn{7}{|c|}{ Parenting style at wave 1} \\
\hline Sensitive & $646(34)$ & $49(22)$ & $168(30)$ & $103(39)$ & $326(38)$ & \\
\hline Normal & $921(49)$ & $95(43)$ & $282(51)$ & $126(48)$ & $418(49)$ & \\
\hline Detached & $325(17)$ & $77(35)$ & $103(19)$ & $32(12)$ & $113(13)$ & $1.7 \mathrm{e}-09$ \\
\hline \multicolumn{7}{|c|}{ Parental investments wave 1} \\
\hline Yes & $1,249(66)$ & $53(24)$ & $345(62)$ & $182(70)$ & $669(78)$ & \\
\hline No & $643(34)$ & $168(76)$ & $208(38)$ & $79(30)$ & $188(22)$ & $8.4 \mathrm{e}-46$ \\
\hline \multicolumn{7}{|c|}{ Parental investments wave 3} \\
\hline Yes & $1,452(77)$ & $89(40)$ & $412(75)$ & $205(79)$ & $746(87)$ & \\
\hline No & $440(23)$ & $132(60)$ & $141(25)$ & $56(21)$ & $111(13)$ & $9.0 \mathrm{e}-30$ \\
\hline Mother tool & parental leav & during first year & & & & \\
\hline Yes & $1,548(82)$ & $116(52)$ & $459(83)$ & $209(80)$ & $764(89)$ & \\
\hline No & $344(18)$ & $105(48)$ & $94(17)$ & $52(20)$ & $93(11)$ & $3.8 \mathrm{e}-21$ \\
\hline Father took & arental leave & luring first year & & & & \\
\hline Yes & $825(44)$ & $29(13)$ & $217(39)$ & $128(49)$ & $451(53)$ & \\
\hline No & $1,067(56)$ & $192(87)$ & $336(61)$ & $133(51)$ & $406(47)$ & $2.8 \mathrm{e}-16$ \\
\hline Number of & orking hours & wave 3 (mother) & & & & \\
\hline Mean (sd) & $17.47(15.48)$ & $8.26(14.00)$ & $17.51(15.43)$ & $18.67(16.13)$ & $19.45(14.84)$ & \\
\hline Median & 20 & 0 & 20 & 20 & 20 & $2.6 \mathrm{e}-11$ \\
\hline Number of & orking hours & wave 4 (mother) & & & & \\
\hline Mean (sd) & $17.60(15.32)$ & $9.27(13.50)$ & $18.57(15.31)$ & $19.54(15.48)$ & $18.54(15.07)$ & \\
\hline Median & 20 & 0 & 20 & 20 & 20 & $3.4 \mathrm{e}-08$ \\
\hline Number of & orking hours & wave 5 (mother) & & & & \\
\hline Mean (sd) & $18.66(14.98)$ & $12.68(14.51)$ & $19.36(15.02)$ & $20.92(15.02)$ & $19.06(14.71)$ & \\
\hline Median & 20 & 7 & 20 & 24 & 20 & $5.1 \mathrm{e}-03$ \\
\hline Number of & orking hours & wave 1 (father) & & & & \\
\hline Mean (sd) & $39.40(15.85)$ & $22.29(20.25)$ & $40.87(13.52)$ & $34.55(17.13)$ & $44.33(11.58)$ & \\
\hline Median & 40 & 25 & 40 & 40 & 42 & $5.6 \mathrm{e}-28$ \\
\hline Number of & orking hours & wave 3 (father) & & & & \\
\hline Mean (sd) & $40.73(14.14)$ & $30.95(19.00)$ & $40.69(13.31)$ & $38.66(14.06)$ & $43.90(11.77)$ & \\
\hline Median & 40 & 40 & 40 & 40 & 40 & $8.1 \mathrm{e}-10$ \\
\hline Number of & orking hours & wave 4 (father) & & & & \\
\hline Mean (sd) & $40.22(12.78)$ & $32.46(18.13)$ & $40.08(11.47)$ & $38.23(12.26)$ & $42.92(11.04)$ & \\
\hline Median & 40 & 40 & 40 & 40 & 40 & $7.3 \mathrm{e}-08$ \\
\hline Number of & orking hours & wave 5 (father) & & & & \\
\hline Mean (sd) & $40.47(13.23)$ & $30.74(18.21)$ & $40.52(11.79)$ & $39.08(13.55)$ & $43.36(11.08)$ & \\
\hline Median & 40 & 40 & 40 & 40 & 40 & $5.5 \mathrm{e}-13$ \\
\hline Child was c & ed for by oth & rs wave 2 & & & & \\
\hline Yes & $761(40)$ & $39(18)$ & $216(39)$ & $115(44)$ & $391(46)$ & \\
\hline No & $1,131(60)$ & $182(82)$ & $337(61)$ & $146(56)$ & $466(54)$ & $3.0 \mathrm{e}-04$ \\
\hline Child was c & ed for by oth & rs wave 3 & & & & \\
\hline Yes & $1,308(69)$ & $96(43)$ & $361(65)$ & $208(80)$ & $643(75)$ & \\
\hline No & $584(31)$ & $125(57)$ & $192(35)$ & $53(20)$ & $214(25)$ & $2.1 \mathrm{e}-04$ \\
\hline Child was c & ed for by oth & rs wave 4 & & & & \\
\hline Yes & $1,405(74)$ & $106(48)$ & $388(70)$ & $212(81)$ & $699(82)$ & \\
\hline No & $487(26)$ & $115(52)$ & $165(30)$ & $49(19)$ & $158(18)$ & $1.3 \mathrm{e}-02$ \\
\hline Child was c & ed for by oth & rs wave 5 & & & & \\
\hline Yes & $1,415(75)$ & $91(41)$ & $399(72)$ & $212(81)$ & $713(83)$ & \\
\hline No & $477(25)$ & $130(59)$ & $154448)$ & $49(19)$ & $144(17)$ & $4.0 \mathrm{e}-02$ \\
\hline Child's Prol & em behavior & DQ) wave 4 & & & & \\
\hline Mean (sd) & $1.25(1.39)$ & $1.67(1.57)$ & $1.29(1.33)$ & $1.16(1.39)$ & $1.14(1.35)$ & \\
\hline Median & 1 & 1 & 1 & 1 & 1 & $2.9 \mathrm{e}-04$ \\
\hline
\end{tabular}

